\title{
Evaluation of the Pollution by Toxic Elements around the Small-Scale Mining Area, Boroo, Mongolia
}

\author{
Bolormaa Oyuntsetseg, ${ }^{1,2}$ Katsunori Kawasaki, ${ }^{3}$ Makiko Watanabe, ${ }^{2}$ \\ and Batkhishig Ochirbat ${ }^{4}$ \\ ${ }^{1}$ School of Chemistry and Chemical Engineering, National University of Mongolia, University Street 1, \\ Ulaanbaatar 14201, Mongolia \\ ${ }^{2}$ Graduate School of Urban Environmental Science, Tokyo Metropolitan University 1-1, Minami-Oosawa, \\ Hachioji-shi, Tokyo 192-039, Japan \\ ${ }^{3}$ Department of Physics, Tokyo Institute of Technology, 2-12-1 Ookayama, Meguro-ku, \\ Tokyo 152-8551, Japan \\ ${ }^{4}$ Institute of Geography, Mongolian Academy of Sciences, Ulaanbaatar 14192, Mongolia
}

Correspondence should be addressed to Bolormaa Oyuntsetseg, bolormaa@num.edu.mn

Received 27 January 2012; Accepted 15 March 2012

Academic Editors: B. J. Birch, A. Lewenstam, S. Polesello, and A. Szemik-Hojniak

Copyright ( $\odot 2012$ Bolormaa Oyuntsetseg et al. This is an open access article distributed under the Creative Commons Attribution License, which permits unrestricted use, distribution, and reproduction in any medium, provided the original work is properly cited.

The objective of this study is to investigate the contamination levels of toxic elements (TEs) in the vicinity of the small-scale mining Boroo area, Mongolia. Samples of surface soil, ground water and human hair were collected around the gold washing or milling places, grassland and village areas. After appropriate preparation, all samples were analyzed for major and toxic elements (TEs) by Particle-Induced X-ray Emission Spectrometry (PIXE). Soil texture, conductivity (EC), pH, total organic carbon (TC) and nitrogen (TN) contents were also measured. The enrichment factor (EF) was estimated to assess the level of the contamination and the possible anthropogenic impact in soils from the mining activity. The $\mathrm{EF}_{\text {soil }}$ for $\mathrm{Cu}, \mathrm{As}$ and $\mathrm{Pb}$ were in the highest values around gold washing place, indicating that around mining area surface soils were highly enriched by those elements. The Mn, Fe and $\mathrm{Ni}$ concentrations of drinking waters exceed the WHO values. The mean concentrations of Ca, Ti, As and Sr were higher in hair of Mongolian miners than in the hair of normal people in Japan, Mongolia and Philippines. These results indicate that the area around gold washing or milling could be the main contamination sources of As and other toxic elements (TEs) in the surface soil samples.

\section{Introduction}

Small-scale mining (artisanal) with metallic mercury is practiced in many developing countries of the world. Smallscale mining is one of the most important sources of toxic elements (TEs) in the environment. Mining generally releases toxic elements such as arsenic (As), cadmium $(\mathrm{Cd})$, lead $(\mathrm{Pb})$, and mercury $(\mathrm{Hg})$. The adverse effects of mining activity on the environment as well as human health have been observed in many countries [1-4]. Environmental pollution with $\mathrm{TE}$ originated by mines can become an important source of contamination both in soil and water [5-8]. Also the TEs contamination of soils and surface water or groundwater represents a great threat to human health due to its high potential to enter into the food chain. Human scalp hair has been used as an alternative biological material for blood and urine in biomonitoring environmental and occupational exposures of various pollutants (papers), since its sampling is considered less invasive, more convenient to store and transport, and less hazardous to handle.

In Mongolia, small-scale mining started in 1998 with few small-scale miners, but the number has increased rapidly. The miners in these areas are almost rural people, who had lost their livestock and harvest during the winter and summer by a natural catastrophe, zud and drought, which happened in recent years. In the Boroo area of Mongolia, which is currently one of the active site for small-scale gold mining, test analyses on soils, river water, and human hair 


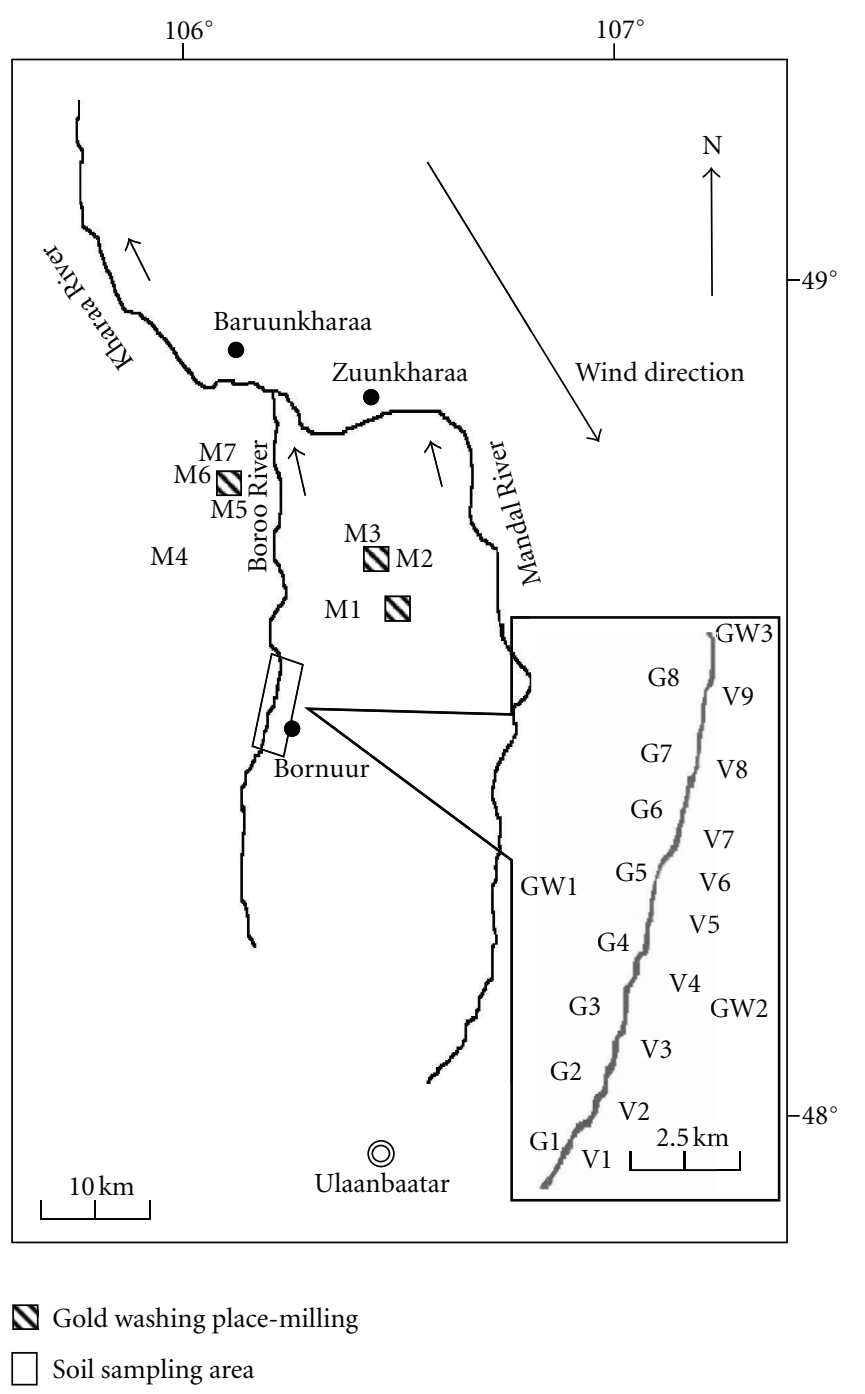

FIgURE 1: Location of sampling sites in the Boroo area, Mongolia.

of toxic contaminants were primarily centered at mercury determination since 1994 (JICA project report). Many analytical methods have been developed for elemental analysis which can be used for environmental pollution analysis in selected areas. Among such methods, the particle-induced Xray emission spectrometry (PIXE) has been widely used for elemental analysis along with neutron and proton activation analyses (NAA, PAA). Our previous studies had concerned with the development of a methodology for total elemental analyses [9-11] in environmental samples by PIXE method. The elemental analysis along Boroo River showed that [9] the contents of TE in the upstream river water were lower than those in the downstream river water, while the $\mathrm{pH}$ was also lower in the downstream river water compared to the upstream river water. It was indicating that the downstream waters might be influenced by gold mining activity in this area. But TEs concentrations in soil, ground water, and other tissues remained poorly documented and required further investigation for environmental assessment of Boroo small-scale mining area. Comparison of TEs in water, soils, sediments, and human hairs (popular for monitoring environmental exposure) would give valuable information on the nature of TE intake (migration in soils, food chain, etc.) by human beings as well as their effect on health condition of selected cohort.

The objective of this study is to determine the heavy metal levels on soil, drinking water, and human hair at the area of the small-scale mining of Boroo area, Mongolia, to disseminate the acquired information to the local people and line ministries. We hope that this paper could be a valuable reference for counter actions to toxic elements pollution.

\section{Materials and Method}

2.1. Study Area. The Bornuur village of the Boroo area, where the study took place, is located in the southwestern part of the North Khentei gold belt at the distance about $120 \mathrm{~km}$ from the capital city Ulaanbaatar of Mongolia (north latitude $48.4^{\circ} \mathrm{C}$, east longitude $106.1^{\circ} \mathrm{C}$ ). In this area the illegal small-scale mining is conducted. Boroo River that 
crosses the gold mining area is an important water supply for agricultural activity. From a geological point of view, in the studied area, the so-called Chara Group of early Paleozoic age (sedimentary rocks) and Boroo gold complex (igneous rocks) of Early Paleozoic age are outcropped. In the area hydrothermal and metasomatic alterations are widely developed, and the mineralized portion includes quartz-gold veins and gold dissemination zone. Constituent minerals of vein are mainly quartz and minor amount of electrum, argentite, pyrite, arsenopyrite, sphalerite, chalcocite, tetrahedrite, galena, tellurobismuthite, albite, and calcite. In our approach, around the gold mining area, when minerals were crushed, some TEs transferred by the wind into the soil under water of the studied area, originating from chiseling, wells, and explosions. The annual average temperature at the site is $17^{\circ} \mathrm{C}$, and the precipitation does not exceed $300 \mathrm{~mm}$ with rainfall which usually occurs in the period between the end of summer and autumn.

2.2. Sampling. The sampling location points are sketched in the map of Figure 1. To provide a satisfactory geographical and human activity representation of the site, the sampling area for surface soils was subdivided into three areas: the grassland $(\mathrm{G})$ representing the control area where 8 samples were taken, the village $(\mathrm{V})$ representing human activities where 9 samples were taken, and the gold washing place of minerals (M) representing the influence of mining activity where 7 samples were taken. Additionally, three ground water samples were taken from the wells (GW1, GW2, and GW3).

Twenty-four soils were taken from a depth of 0.2 $10 \mathrm{~cm}$ under the surface, in order to avoid contamination or removal of TEs from the surface by the wind. The soil samples were air-dried and sieved by $2 \mathrm{~mm}$ sieve prior to chemical analysis. The drinking water samples were taken from acting wells used by the local population ( 3 samples with duplicates in total, each of $100 \mathrm{~mL}$, were taken). The water samples were taken in acid-washed plastic bottles and acidified $(\mathrm{pH}<2)$ with $\mathrm{HNO}_{3}$. All the samples were kept refrigerated at $4^{\circ} \mathrm{C}$ prior to the analysis. Human hair samples were asked from 25 miners and 20 local residents not involved in the mining activity. The samples thoroughly washed to remove external contamination by $1 \%$ soap solution, acetone, and distilled water prior chemical analysis.

2.3. Chemical Analysis. The chemical properties of soil samples were investigated by using the standard methods of analytical chemistry. The $\mathrm{pH}$ of the soil was measured by the use of a Toko, TPX-90i pH meter, made in Japan. In order to measure the $\mathrm{pH}$ of the soil, the soil was added in a $1 \mathrm{M}-\mathrm{KCl}$ solution, in ratio of $1: 2.5$. Electrical conductivity (EC) was measured by a Horiba, EC-51 conductivity meter, made in Japan. The TC and TN contents were analyzed using a CN analyzer (Sumika, Sumigraph NC-80). Particle size distribution ( $\mathrm{wt} \%$ ) was investigated by using the pipette method [12]. Elemental analysis of soil samples after acid digestion was carried out by a previously developed USA methodology for PIXE [11]. The $\mathrm{pH}$ of water samples was measured by electrode method using a $\mathrm{pH}$ meter (Toko,
TPX-90i, Japan). Trace and TE contents in drinking water were determined according to the methodology described by Bolormaa et al. [9].

The dissolution of human hair samples was carried out by a mixture of nitric acid $\left(\mathrm{HNO}_{3}\right)$ and hydrogen peroxide $\left(\mathrm{H}_{2} \mathrm{O}_{2}\right)$. The ratio of the acid should be given. The methodology of elemental analysis for human hair including the accuracy and precision is reported in Bolormaa O. et al. [10]. The relationship between metal concentration in soil and human hair samples was tested by Pearson's correlation coefficients $(r)$. Coefficients of correlation were calculated at the significance level $P \leq 0.05$.

All the chemicals were supplied by Wako Pure Chemical Co.Ltd. (Osaka, Japan), and used without future purification.

2.4. The PIXE Technique. The targets prepared following the procedures above were irradiated by $2.5 \mathrm{MeV}$ proton beam from the single-end-type Van de Graaff accelerator of Tokyo Institute of Technology (Tokyo, Japan). The proton beam was collimated to give a beam size of about $5 \mathrm{~mm}$ in diameter at the collimator exit. Emitted X-rays were analyzed using an ORTEC (Tennessee, USA) Si (Li) detector (active volume $0.45 \mathrm{~cm}^{3}$, effective diameter $10 \mathrm{~mm}$, thickness $5.67 \mathrm{~mm}$, distance from window $7 \mathrm{~mm}$, FWTES of $\mathrm{FeK}_{\alpha} \mathrm{X}$ Ray $180 \mathrm{eV}$ ) with a $1 \mathrm{~mm}$ polyethylene absorber and CANBERRA (Meriden, USA) Si (Li) detector (effective diameter $4 \mathrm{~mm}$, thickness $3 \mathrm{~mm}$, distance from window $5 \mathrm{~mm}$, FWTES of $\mathrm{FeK}_{\alpha} \mathrm{X}$-Ray $160 \mathrm{eV}$ ) without an absorber. The beryllium window was $25 \mu \mathrm{m}$ in thickness for both detectors. The first detector was used for measurement of heavy elements $(Z>$ $25)$ and the second for light or major elements $(Z<25)$. For soil samples we used $\mathrm{Si}(\mathrm{Li})$ detector (active volume $0.45 \mathrm{~cm}^{3}$, effective diameter $10 \mathrm{~mm}$, thickness $5.67 \mathrm{~mm}$, distance from window $7 \mathrm{~mm}$, FWTES of $\mathrm{FeK}_{\alpha} \mathrm{X}$-Ray $180 \mathrm{eV}$ ) with a $2 \mathrm{~mm}$ polyethylene absorber to avoid the effect of pile up associated with the $\mathrm{FeK}_{\alpha}$ line in view of the high iron concentration in soil samples. The analysis of the X-rays was performed using PIXE2 software (http://www.Labo-eq.co.jp/). Major elements $(Z<25)$ of the samples (soil, water, human hair) analyzed by drop-and-dry method. For this procedure, a $20 \mu \mathrm{L}$ aliquot of the mixture from sample was dropped onto Nuclepore Track-Etch Membrane (Whatman, New Jersey, USA), air-dried, and irradiated by proton beam. For TEs $(Z>25)$ the pre-concentration method (water samples treated to form metal dibenzyldithiocarbamate (DBDTC) complexes) was applied and molybdenum (Mo) was used as an internal standard. Since the elements of low-energy region in the elemental spectra are covered by sulfur (S), which forms complexes with DBDTC, major elements could not be determined in water samples by preconcentration method. The X-ray spectra analysis was performed by using PIXE 2 software package, which is produced by the Laboratory Equipment Co., Ltd. (Japan) (http://www.Labo-eq.co.jp/). Since the energy of $\mathrm{PbL}_{\alpha}$ and $\mathrm{AsK}_{\alpha} \mathrm{X}$-rays is almost identical, As and $\mathrm{Pb}$ could not be distinguished in the spectrum. Therefore, $\mathrm{AsK}_{\beta}$ was used to correct the contribution of $\mathrm{AsK}_{\alpha}$ to $\mathrm{PbL}_{\alpha}$. 
TABLE 1: Physicochemical characteristics of soil samples.

\begin{tabular}{|c|c|c|c|c|c|c|c|c|}
\hline \multirow{2}{*}{ Sampling site } & \multicolumn{8}{|c|}{ Characteristics } \\
\hline & $\mathrm{pH}$ (water) & $\mathrm{EC}, \mathrm{mS} / \mathrm{m}$ & $\mathrm{Ng} \mathrm{kg}^{-1}$ & $\mathrm{C}, \mathrm{g} \mathrm{kg}^{-1}$ & $\mathrm{C} / \mathrm{N}$ & Cly [\%] & Silt [\%] & Sand [\%] \\
\hline \multicolumn{9}{|c|}{ Grassland $(n=8)$} \\
\hline Range & $7.76-8.74$ & $3.53-10.1$ & $1.03-2.13$ & $15-25.8$ & $10.80-16.84$ & $10.53-21.54$ & $10.89-23.54$ & $55.71-78.57$ \\
\hline Mean & 8.45 & 6.95 & 1.61 & 20.95 & 13.3 & 16.92 & 15.81 & 67.28 \\
\hline \multicolumn{9}{|l|}{ Village $(n=9)$} \\
\hline Range & $7.72-9.09$ & $2.02-17.59$ & $0.993-3.36$ & $16.37-35.45$ & $9.70-17.32$ & $15.27-27.57$ & $13.43-38.18$ & $41.85-70.94$ \\
\hline Mean & 8.46 & 7.16 & 1.74 & 22.04 & 13.69 & 19.43 & 20.76 & 59.81 \\
\hline \multicolumn{9}{|c|}{$\begin{array}{l}\text { Gold washing place } \\
(n=7)\end{array}$} \\
\hline Range & $7.86-8.76$ & $2.59-28.2$ & $0.37-5.30$ & $5.40-57.61$ & $10.86-14.70$ & $11.79-21.31$ & $15.58-36.97$ & $47.18-70.14$ \\
\hline Mean & 8.20 & 13.29 & 2.41 & 29.13 & 12.86 & 17.07 & 21.29 & 61.61 \\
\hline
\end{tabular}

$n$ : number of samples, mean value: three replicates of each soil data.

\section{Results and Discussion}

3.1. Soil Properties and Elemental Concentrations. The mean and range of soil $\mathrm{pH}$ values are shown in Table 1 . The results showed slightly alkaline values varying from 8.20 to 8.45 . The EC values also varied between samples, in a range from 6.95 to $13.29 \mathrm{mS} \mathrm{m}^{-1}$. The EC value near the gold washing place of ore was higher than grassland and village areas in effluent draining from the mine wastes. Total $\mathrm{C}$ and $\mathrm{N}$ contents varied from 5.40 to $57.6 \mathrm{~g} \mathrm{~kg}^{-1}$ and from 0.37 to $5.30 \mathrm{~g} \mathrm{~kg}^{-1}$, respectively. The relative percentage of clay, silt and sand in the soils were in the range $0.53-27.57 \%, 10.89$ $38.18 \%$, and $41.85-78.57 \%$, respectively. The texture of most of soils was classified as clay (C) and silty clay loam (SiCL). The contents of major elements in soil samples measured by PIXE are shown in Table 2 . The results indicate that the soil samples have elevated Ca (24844-98334 $\mathrm{mg} \mathrm{kg}^{-1}$ ) and $\mathrm{Cl}$ (6092-33356 $\mathrm{mg} \mathrm{kg}^{-1}$ ) contents in the gold washing area. The soil samples in this study showed alkaline $\mathrm{pH}$ and high Ca content, suggesting that considerable amount of $\mathrm{CaCO}_{3}$ might be present in these soils. The alkaline $\mathrm{pH}$ of the soils in the studied area and the high content of calcium play an important role in metal stability, in such a way that there is no transfer of soluble TEs and they are being only mobilized in particulate form. Consequently, the decreases in $\mathrm{pH}$ mobilize significant amount of the metals which are present in these soils since carbonates are one of the major sinks for TEs [13]. The behavior and bioavailability of the TEs in soil are primarily controlled by $\mathrm{pH}$. Figure 2 shows the concentrations of $\mathrm{Cu}, \mathrm{Zn}, \mathrm{As}, \mathrm{Sr}$, and $\mathrm{Pb}$ in different sites of the three studied areas. In the grassland area, however, the average concentrations of $\mathrm{Cu}$ and $\mathrm{Zn}$ are close to the world average of 30 and $90 \mathrm{mg} \mathrm{kg}^{-1}$ respectively, reported by Bowen [14], while the mean contents of Sr for the studied areas varied from 13.9 to $202 \mathrm{mg} \mathrm{kg}^{-1}$ which are lower than world average of $240 \mathrm{mg} \mathrm{kg}^{-1}$. The concentration of $\mathrm{Cu}$ in the site M6 of gold washing area was $407 \mathrm{mg} \mathrm{kg}^{-1}$, exceeding the concentration of $35 \mathrm{mg} \mathrm{kg}^{-1}$ reported by Bowen [14]. Elevated concentrations of $\mathrm{Zn}$ were found in surface soils at the gold washing area and village, ranging from 29.2 to $223 \mathrm{mg} \mathrm{kg}^{-1}$. Soil texture has a major influence on trace metal concentrations, with heavy textured soils higher concentrations of $\mathrm{Cd}, \mathrm{Co}, \mathrm{Cr}, \mathrm{Cu}, \mathrm{Ni}$, and $\mathrm{Zn}$ then light soils having higher $\mathrm{Pb}$ concentrations than other soils [15]. In the contrast of this, in our study $\mathrm{Pb}$ concentration was higher in clay loam soils around the gold washing place. The $\mathrm{Pb}$ content was 637 and $257 \mathrm{mg} \mathrm{kg}^{-1}$ at the sites V1 and V3. For village, $\mathrm{Pb}$ can increase through its various applications such as automobile components, solder in electronics and lead batteries. Near the gold washing place, at the sites M2 and M5 the $\mathrm{Pb}$ contents were 231 , and $236 \mathrm{mg} \mathrm{kg}^{-1}$. Arsenic contents were at the sites M2 M7, 573 and $245 \mathrm{mg} \mathrm{kg}^{-1}$, respectively, around gold washing place. It illustrates that gold washing place was significantly affected by waste tailings from mining. The elevated concentrations of $\mathrm{As}$ and $\mathrm{Pb}$ are a matter of serious concern because they are carcinogenic, toxic at low concentrations, and bioaccumulative in organisms. The TEs analysis showed that near the gold washing place soils where polluted by TEs such as $\mathrm{Cu}$, As, and $\mathrm{Pb}$. The contents of $\mathrm{Cu}, \mathrm{Zn}, \mathrm{As}$, and $\mathrm{Pb}$ in soil around gold washing place are separately $109,146,167$, and $86 \mathrm{mg} / \mathrm{kg}$ in average, which are 3.6, 1.6, 27.8, and 2.5 times those of [14]. A major source of the TEs in the gold-mining area is the oxidation of sulphide minerals, since most of the TEs are known to occur mainly as sulphides and associated with gold minerals. In the process of mineral crushing and other mining activities, these TEs can be released in the environment.

Finally, enrichment factor (EF) was used to assess the level of the contamination and the possible anthropogenic impact in soils from the mining activity. To identify unexpected metal concentration, geochemical normalization of the TEs concentrations with respect data to a conservative element, such as $\mathrm{Al}, \mathrm{Fe}$, and $\mathrm{Si}$, was employed. Several authors have successfully used iron to normalize heavy metal contaminants [16, 17]. In this study, the iron was used as an element to differentiate natural from anthropogenic components. The enrichment factor of soil $\left(\mathrm{EF}_{\text {soil }}\right)$ is relative abundance, with regards to iron, of one element $(\mathrm{M})$ in a soil compared to its relative abundance $(\mathrm{M} / \mathrm{Fe})$ in control site: $\mathrm{EF}_{\text {soil }}=(\mathrm{M} / \mathrm{Fe})_{\text {soil }} /(\mathrm{M} / \mathrm{Fe})_{\text {control }}$. Table 3 shows EF values of $\mathrm{Cu}, \mathrm{Zn}, \mathrm{As}, \mathrm{Sr}$, and $\mathrm{Pb}$ for grassland, village, and gold washing places. The $\mathrm{EF}_{\text {soil }}$ for $\mathrm{Cu}, \mathrm{As}$, and $\mathrm{Pb}$ had the highest around 


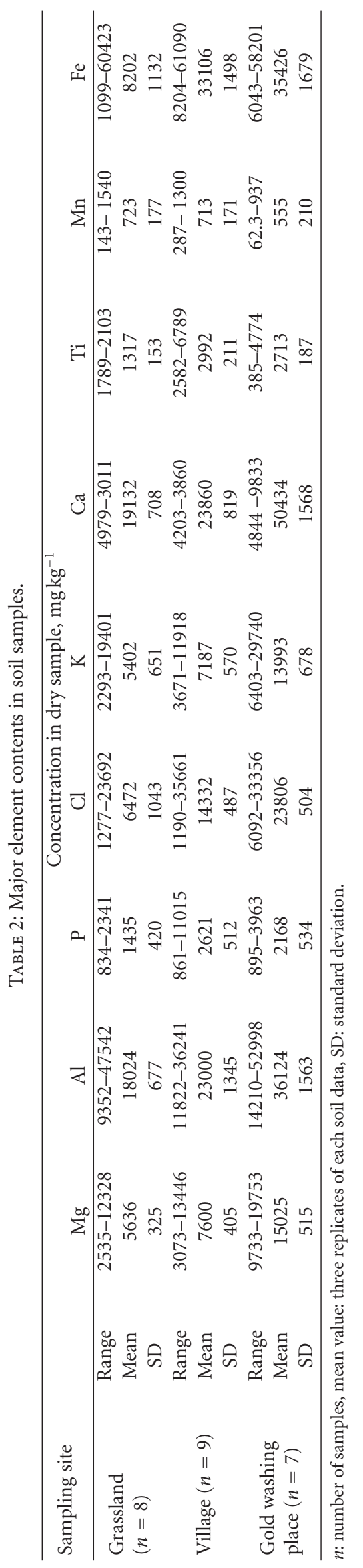




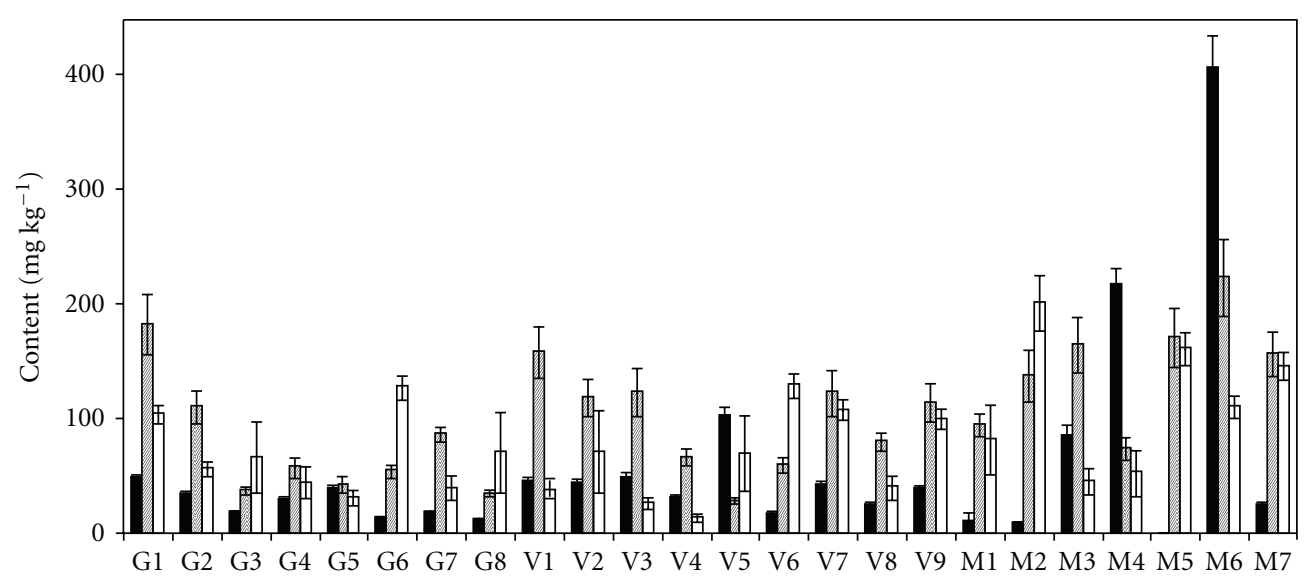

Site

(a)

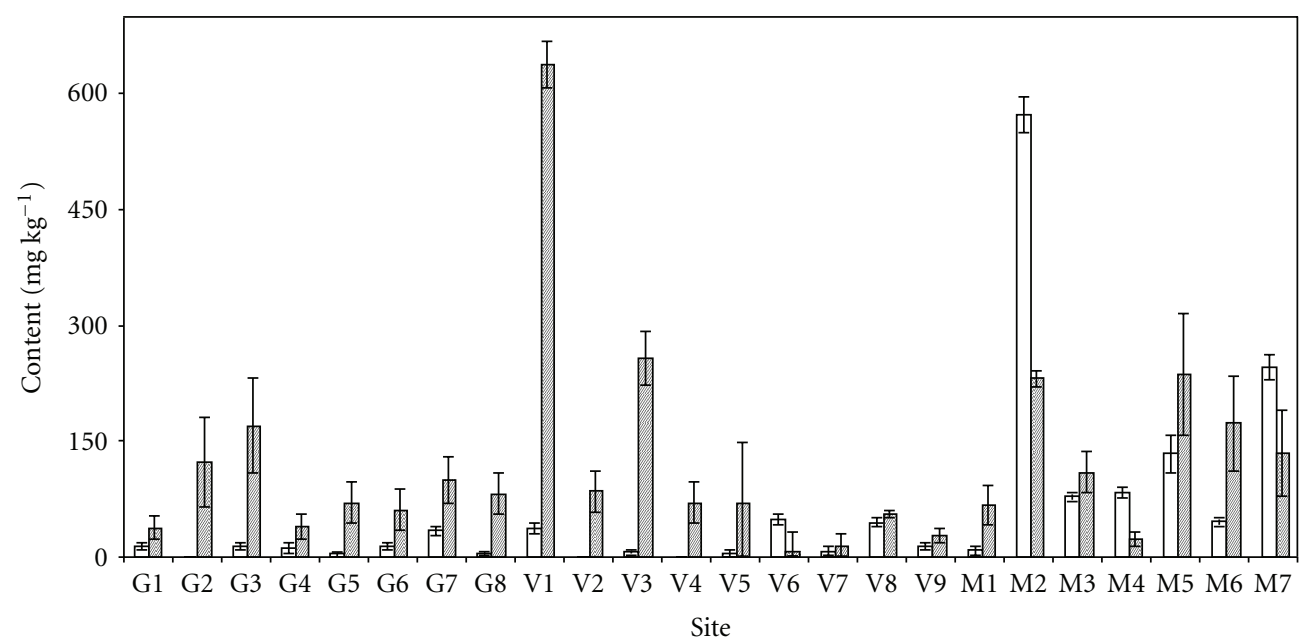

$\square$ As

口 $\mathrm{Pb}$

(b)

Figure 2: Contents of toxic elements in surface soil samples (a) for $\mathrm{Zn}, \mathrm{Cu}, \mathrm{Sr}$ and (b) for As and $\mathrm{Pb}$.

TABLE 3: Enrichment factor of the determined toxic elements in the areas of grassland, village, and gold washing.

\begin{tabular}{lccc}
\hline Element & \multicolumn{3}{c}{$\begin{array}{c}\text { Enrichment factor } \\
\text { Village }\end{array}$} \\
\hline $\mathrm{Cu}$ & 1.29 & 1.56 & 4 \\
$\mathrm{Zn}$ & 1.21 & 1.14 & 1.79 \\
$\mathrm{As}$ & 3.26 & 3.34 & 30.52 \\
$\mathrm{Sr}$ & 0.39 & 0.28 & 0.51 \\
$\mathrm{~Pb}$ & 3.49 & 4.08 & 4.37 \\
\hline
\end{tabular}

the gold washing place, indicating that around mining area soil was highly enriched by those elements.
More interesting information was extracted from correlation analysis between contents of the determined elements for the different studied areas. A considerably significant high correlation was observed between $\mathrm{Mn}-\mathrm{Fe}$ for the village $(r=0.927)$ and the gold washing $(r=0.905)$ places. In the gold washing place, there were significant correlations for $\mathrm{Sr}-$ $\mathrm{Pb}(r=0.847), \mathrm{Mn}-\mathrm{As}(r=-0.773), \mathrm{Fe}-\mathrm{As}(r=-0.774)$ and As-Sr $(r=0.778)$ which reflects the presence of TEs in the minerals of these areas.

3.2. Concentrations of TEs in Ground Water. The concentration of major and TEs in drinking water are given in Table 4. The various TEs present in ground water are originated from the anthropogenic activities and compositions of the soils and rocks it comes into contact with. Also the mobility 
TABLE 4: Analytical data of drinking water samples.

\begin{tabular}{|c|c|c|c|c|}
\hline \multirow{2}{*}{ Parameters } & \multirow{2}{*}{ UM } & \multicolumn{3}{|c|}{ Sample ID } \\
\hline & & GW1 & GW2 & GW3 \\
\hline $\mathrm{pH}$ & & 8.34 & 8.64 & 8.71 \\
\hline $\mathrm{Na}$ & ppm & $11.2 \pm 0.2$ & $10.3 \pm 0.1$ & $21.5 \pm 1.2$ \\
\hline $\mathrm{Mg}$ & ppm & $5.11 \pm 0.2$ & $9.05 \pm 0.2$ & $24.6 \pm 1.9$ \\
\hline $\mathrm{Al}$ & ppm & $0.982 \pm 0.122$ & $0.524 \pm 0.145$ & $0.481 \pm 1.142$ \\
\hline $\mathrm{Si}$ & ppm & $8.12 \pm 0.40$ & $10.2 \pm 0.5$ & $11.8 \pm 0.6$ \\
\hline S & ppm & $7.41 \pm 0.24$ & $16.9 \pm 1.6$ & $26.1 \pm 2.1$ \\
\hline $\mathrm{Cl}$ & ppm & $11.0 \pm 0.2$ & $12.3 \pm 0.3$ & $25.7 \pm 1.5$ \\
\hline K & ppm & $2.50 \pm 0.17$ & $1.35 \pm 0.15$ & $2.62 \pm 0.21$ \\
\hline $\mathrm{Ca}$ & ppm & $31.0 \pm 1.3$ & $16.2 \pm 1.2$ & $32.3 \pm 1.9$ \\
\hline $\mathrm{Mn}$ & ppm & $1.28 \pm 0.21$ & $2.79 \pm 0.4$ & $0.57 \pm 0.07$ \\
\hline $\mathrm{Fe}$ & ppm & $65 \pm 2.3$ & $59 \pm 2.1$ & $14.5 \pm 1.2$ \\
\hline $\mathrm{Ni}$ & ppm & $0.54 \pm 0.08$ & $0.65 \pm 0.08$ & $0.41 \pm 0.1$ \\
\hline $\mathrm{Cu}$ & ppm & $8.6 \pm 1.2$ & $1.7 \pm 0.3$ & $1.3 \pm 0.2$ \\
\hline $\mathrm{Zn}$ & ppm & $5.3 \pm 0.4$ & $39 \pm 2.1$ & $9.5 \pm 0.9$ \\
\hline As & ppm & $<\operatorname{LOD}(<0.002)$ & $<\mathrm{LOD}$ & $<\mathrm{LOD}$ \\
\hline $\mathrm{Pb}$ & ppm & $<\operatorname{LOD}(0.001)$ & $<\mathrm{LOD}$ & $<\mathrm{LOD}$ \\
\hline
\end{tabular}

TABLE 5: Intercomparison of trace element concentrations $\left(\mathrm{mg} \mathrm{kg}^{-1}\right)$ in human hair.

\begin{tabular}{|c|c|c|c|c|c|c|}
\hline \multirow{2}{*}{ Element } & \multirow[t]{2}{*}{$\mathrm{UM}$} & \multicolumn{2}{|c|}{ Our study (PIXE) } & \multirow{2}{*}{$\begin{array}{c}\text { Japan (PIXE) } \\
\text { normal [21] }\end{array}$} & \multirow{2}{*}{$\begin{array}{c}\text { Mongolia } \\
\text { (PIXE) } \\
\text { normal }[20]\end{array}$} & \multirow{2}{*}{$\begin{array}{c}\text { Philippines } \\
\text { (PIXE) miners } \\
\text { [19] }\end{array}$} \\
\hline & & $\begin{array}{l}\text { Normal } \\
(n=20)\end{array}$ & $\begin{array}{l}\text { Miners } \\
(n=25)\end{array}$ & & & \\
\hline $\mathrm{Ca}$ & ppm & 2096 & $524-2259$ & 1890 & 411 & $383.1-5363$ \\
\hline $\mathrm{Ti}$ & ppm & 80.4 & $21.8-42.2$ & 10.4 & 17.6 & $0-6.2$ \\
\hline $\mathrm{Mn}$ & ppm & 7.93 & $1.6-43.1$ & 1.62 & 9.5 & $0.1-289.6$ \\
\hline $\mathrm{Fe}$ & ppm & 25.1 & $52.1-142$ & 29.1 & 126 & $10.8-222.1$ \\
\hline $\mathrm{Ni}$ & ppm & 1.7 & $0.2-4.9$ & 2.05 & 1.6 & $0-3.5$ \\
\hline $\mathrm{Cu}$ & ppm & 4.9 & $3.5-17.9$ & 42.7 & 13.7 & $5.6-138.2$ \\
\hline $\mathrm{Zn}$ & ppm & 452 & 155-293 & 238 & 218 & $55-972.9$ \\
\hline As & ppm & 1.8 & $2.1-5.5$ & 0.23 & 1.3 & $0-9$ \\
\hline $\mathrm{Pb}$ & ppm & 8 & $5.4-28.9$ & 37.3 & 6.6 & $1.1-87.5$ \\
\hline $\mathrm{Sr}$ & ppm & 3.3 & $7.5-22.6$ & 6.04 & 3.9 & 0 \\
\hline
\end{tabular}

and behavior of TEs in natural waters largely depend on $\mathrm{pH}$. The $\mathrm{pH}$ of the ground water samples is ranging from 8.34 to 8.71 , showing slightly alkaline values due to natural and anthropogenic origin. The contents of $\mathrm{Fe}, \mathrm{Cu}$, and $\mathrm{Zn}$ are ranging in $14.5-65 \mathrm{mg} \mathrm{L}^{-1}, 1.3-8.6 \mathrm{mg} \mathrm{L}^{-1}$, and 5.3-39 $\mathrm{mg} \mathrm{L}^{-1}$, respectively. The samples GW1 and GW2 showed the highest $\mathrm{Cu}$ and $\mathrm{Zn}$ values 86 and $390.5 \mathrm{mg} \mathrm{L}^{-1}$ respectively, which were above the WHO maxima allowed concentrations 2 and $150.5 \mathrm{mg} \mathrm{L}^{-1}$, respectively [18]. Further from Table 3, it is seen that the concentrations of $\mathrm{Mn}$ are ranging from 0.5 to $2.79 \mathrm{mg} \mathrm{L}^{-1}$, while $\mathrm{Ni}$ concentration varies between 0.41 and $0.652 .79 \mathrm{mg} \mathrm{L}^{-1}$. The $\mathrm{Mn}, \mathrm{Fe}$, and $\mathrm{Ni}$ concentrations of drinking waters exceed the WHO values: $0.5 \mathrm{mg} \mathrm{L}^{-1}, 0.1 \mathrm{mg} \mathrm{L}^{-1}$, and $0.1 \mathrm{mg} \mathrm{L}^{-1}$ for $\mathrm{Mn}, \mathrm{Fe}$, and $\mathrm{Ni}$, respectively. Among the TEs, $\mathrm{As}$ and $\mathrm{Pb}$ are highly toxic even at very low levels and are classified as a possible human carcinogens. The concentrations of As and $\mathrm{Pb}$ in the potable water samples were lower than the maximum allowed values according to the US Environmental Protection Agency (EPA) level of $10 \mu \mathrm{g} \mathrm{L}^{-1}$ and $15 \mu \mathrm{g} \mathrm{L}^{-1}$ for As and $\mathrm{Pb}$ in drinking water.

3.3. TEs in Human Hair of Miners. After acid digestion of human hair samples, a $20 \mu \mathrm{l}$ aliquot of the solution was dropped, air-dried on the Nuclepore track etch membrane (Whatman, New Jersey, USA), and irradiated by the $2.5 \mathrm{MeV}$ proton beam from the single-end-type Van de Graaff accelerator. The elemental concentrations in biological samples vary considerably due to geographical differences, nutritional status, and environmental factors. The present results were 
compared with other results reported by several researchers and the ranges of worldwide mean values. Table 5 shows the comparative results. The mean concentrations of $\mathrm{Ca}$, Ti, As, and $\mathrm{Sr}$ in Mongolian miner's hair were higher than those in the hair of noncontaminated people in Japan, Mongolia, and Philippines $[19,20]$. The level of $\mathrm{Cu}, \mathrm{Zn}$, and $\mathrm{Mn}$ is not higher in the hair samples from the people in these countries. The maximum concentrations for $\mathrm{As}$ and $\mathrm{Pb}, 5.5$ and $38.9 \mathrm{ppm}$, are clearly higher than those normal Japanese people which are 0.25 and $29.2 \mathrm{ppm}$ (Sera K. et al., [21]). It is shown that the difference of the average element contents in hair of healthy people and miners, in most cases, is statistically not significant. The positive correlations were observed for $\mathrm{Zn}$ and Fe; $\mathrm{Mn}$ and $\mathrm{Ca}$; $\mathrm{Sr}$ and $\mathrm{Zn}$ of miners. The correlation matrix gives us information about relationships between two metals but does not take into consideration of the presence of other elements.

\section{Conclusions}

The present study evaluated the levels of TEs $(\mathrm{Mn}, \mathrm{Cu}$, $\mathrm{Ni}, \mathrm{Zn}, \mathrm{As}, \mathrm{Sr}$, and $\mathrm{Pb}$ ) in surface soils, human hair, and potable water around the small-scale mining of Boroo area, Mongolia. The surface soil samples in this study showed alkaline $\mathrm{pH}$ and high $\mathrm{Ca}$ content, suggesting that considerable amount of $\mathrm{CaCO}_{3}$ might be present in these soils. The soil of gold washing area is polluted by $\mathrm{Cu}$, As, and $\mathrm{Pb}$. The contents of $\mathrm{Cu}, \mathrm{Zn}, \mathrm{As}$, and $\mathrm{Pb}$ in soil around the gold washing place were $109,146,167$, and $86 \mathrm{mg} / \mathrm{kg}$ in average, respectively, which were $3.6,1.6,27.8$, and 2.5 times those of the reference. Significant correlation was observed around gold washing place between $\mathrm{Mn}-\mathrm{Fe}, \mathrm{Mn}-\mathrm{As}$, As$\mathrm{Sr}$, and $\mathrm{Sr}-\mathrm{Pb}$ reflecting the presence of TEs in the soils of these areas. Also, the $\mathrm{EF}_{\text {soil }}$ was for $\mathrm{Cu}, \mathrm{As}$, and $\mathrm{Pb}$ in the highest values around the gold washing area, indicating that the soils around mining area were highly enriched by those elements. The $\mathrm{Mn}, \mathrm{Fe}$, and $\mathrm{Ni}$ concentrations of drinking waters exceeded the maximum values allowed by the WHO: $0.5 \mathrm{mg} \mathrm{L}^{-1}, 0.1 \mathrm{mg} \mathrm{L}^{-1}$, and $0.1 \mathrm{mg} \mathrm{L}^{-1}$ for $\mathrm{Mn}, \mathrm{Fe}$, and $\mathrm{Ni}$, respectively. The mean concentrations of $\mathrm{Ca}, \mathrm{Ti}, \mathrm{As}$, and $\mathrm{Sr}$ in hair of Mongolian miners were higher than those in the hair of noncontaminated people in Japan, Mongolia, and Philippines. Positive correlations were observed for $\mathrm{Zn}$ and $\mathrm{Fe}, \mathrm{Mn}$, and $\mathrm{Ca}, \mathrm{Sr}$ and $\mathrm{Zn}$ in the hair samples of the miners. This study showed that environmental pollution around the small-scale mining gives a serious attention to local government and responsible environmental regulation bodies.

\section{Acknowledgments}

The authors wish to thank Professor Kh. Tsookhuu, National University of Mongolia, for his great help in field trip. B. Oyuntsetseg is most grateful to the Japanese Society for Promotion of Science (JSPS) for the financial support. The authors wish to thank the anonymous reviewers for constructive comments.

\section{References}

[1] A. Samecka-Cymerman and A. J. Kempers, "Toxic metals in aquatic plants surviving in surface water polluted by copper mining industry," Ecotoxicology and Environmental Safety, vol. 59, no. 1, pp. 64-69, 2004.

[2] A. Boularbah, C. Schwartz, G. Bitton, and J. L. Morel, "Heavy metal contamination from mining sites in South Morocco: 1. Use of a biotest to assess metal toxicity of tailings and soils," Chemosphere, vol. 63, no. 5, pp. 802-810, 2006.

[3] G. L. Liao, D. X. Liao, and Q. M. Li, "TEs contamination characteristics in soil of different mining activity zones," Transactions of Nonferrous Metals Society of China, vol. 18, no. 1, pp. 207-211, 2008.

[4] H. S. Lim, J. S. Lee, H. T. Chon, and M. Sager, "Heavy metal contamination and health risk assessment in the vicinity of the abandoned Songcheon Au-Ag mine in Korea," Journal of Geochemical Exploration, vol. 96, no. 2-3, pp. 223-230, 2008.

[5] B. J. Alloway, "The origins of TEs in soils," in TEs in Soils, B. J. Alloway, Ed., Blackie Academic \& Professional, New York, NY, USA, 1995.

[6] M. C. Jung, "Heavy metal contamination of soils and waters in and around the Imcheon Au-Ag mine, Korea," Applied Geochemistry, vol. 16, no. 11-12, pp. 1369-1375, 2001.

[7] V. Chatain, F. Sanchez, R. Bayard, P. Moszkowicz, and R. Gourdon, "Effect of experimentally induced reducing conditions on the mobility of arsenic from a mining soil," Journal of Hazardous Materials, vol. 122, no. 1-2, pp. 119-128, 2005.

[8] A. Concas, C. Ardau, A. Cristini, P. Zuddas, and G. Cao, "Mobility of heavy metals from tailings to stream waters in a mining activity contaminated site," Chemosphere, vol. 63, no. 2, pp. 244-253, 2006.

[9] O. Bolormaa, J. Baasansuren, K. Kawasaki, M. Watanabe, and T. Hattori, "PIXE analysis of heavy metals in water samples from a mining area in Mongolia," Nuclear Instruments and Methods in Physics Research B, vol. 243, no. 1, pp. 161-166, 2006.

[10] O. Bolormaa, M. Tsuji, K. Kawasaki, S. Narantsetseg, and T. Hattori, "PIXE analysis of trace elements in human hair of patients with liver disorders," International Journal of PIXE, vol. 16, no. 1-2, pp. 29-38, 2006.

[11] O. Bolormaa, J. Baasansuren, K. Kawasaki, M. Watanabe, and T. Hattroi, "Total elemental composition analysis of soil samples using the PIXE technique," Nuclear Instruments and Methods in Physics Research B, vol. 262, no. 2, pp. 385-390, 2007.

[12] International Organization for Standardization (ISO), "Determination of particle size distribution by gravitational liquid sedimentation methods-part 2: fixed pipette method," ISO 13317-2, 2001.

[13] X. Li and I. Thornton, "Chemical partitioning of trace and major elements in soils contaminated by mining and smelting activities," Applied Geochemistry, vol. 16, no. 15, pp. 16931706, 2001.

[14] H. J. M. Bowen, Environmental Chemistry of the Elements, Academic Press, New York, NY, USA, 1979.

[15] F. J. Zhao, S. P. McGrath, and G. Merrington, "Estimates of ambient background concentrations of trace metals in soils for risk assessment," Environmental Pollution, vol. 148, no. 1, pp. 221-229, 2007.

[16] A. P. Mucha, M. T. S. D. Vasconcelos, and A. A. Bordalo, "Macrobenthic community in the Douro estuary: relations with trace metals and natural sediment characteristics," Environmental Pollution, vol. 121, no. 2, pp. 169-180, 2003. 
[17] S. R. Oliva and A. J. F. Espinosa, "Monitoring of heavy metals in topsoils, atmospheric particles and plant leaves to identify possible contamination sources," Microchemical Journal, vol. 86, no. 1, pp. 131-139, 2007.

[18] Guidelines for Drinking-Water Quality, vol. 1, WHO, Geneva, Switzerland, 2nd edition, 1993, http://www.Labo-eq.co.jp/.

[19] S. Murao, E. Daisa, K. Sera, V. B. Maglambayan, and S. Futatsugawa, "PIXE measurement of human hairs from a smallscale mining site of the Philippines," Nuclear Instruments and Methods in Physics Research B, vol. 189, no. 1-4, pp. 168-173, 2002.

[20] S. Murao, K. Sera, B. Tumenbayar, M. Tsuji, S. Futatsugawa, and T. Waza, "Finding high level arsenic for Mongolian villagers' hair through PIXE technique," in Proceedings of the 16th International Conference 8 on Ion Beam Analysis, pp. 1024, Albuquergue, NM, USA, June 2003.

[21] K. Sera, S. Futatsugawa, and S. Murao, "Quantitative analysis of untreated hair samples for monitoring human exposure to heavy metals Nucl. Inst. and Meth," Physiological Research, vol. B189, no. 1-4, pp. 174-179, 2002. 


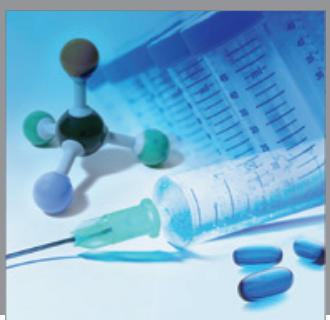

International Journal of

Medicinal Chemistry

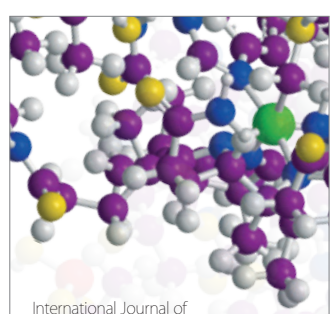

Carbohydrate Chemistry

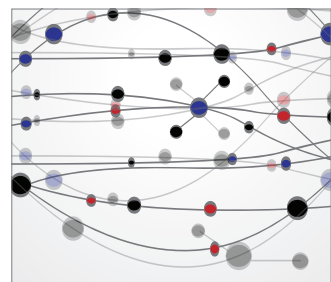

The Scientific World Journal
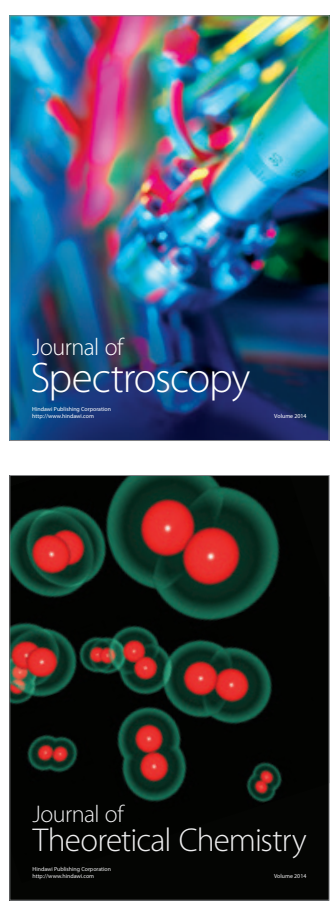
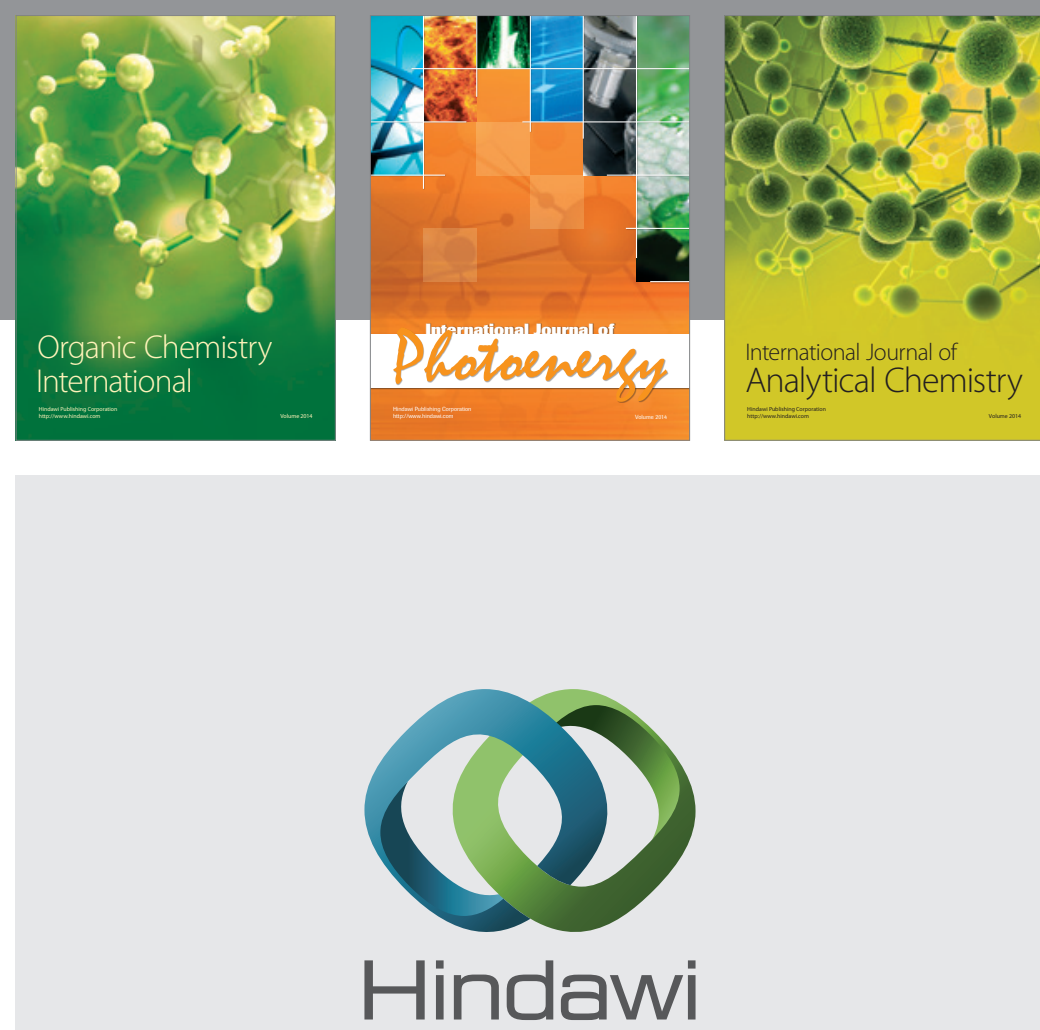

Submit your manuscripts at

http://www.hindawi.com
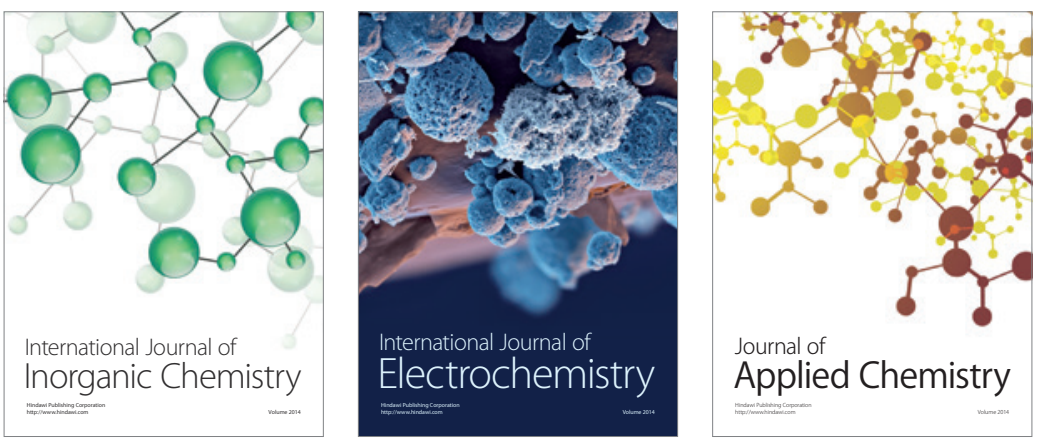

Journal of

Applied Chemistry
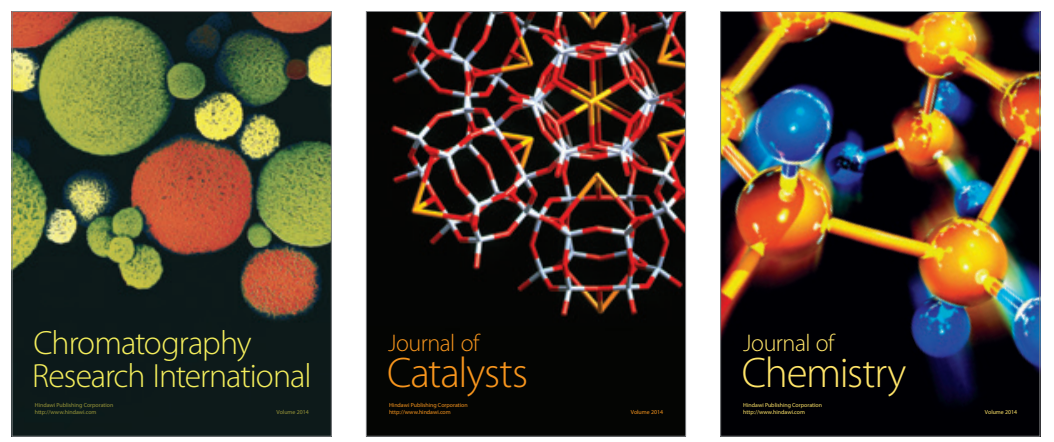
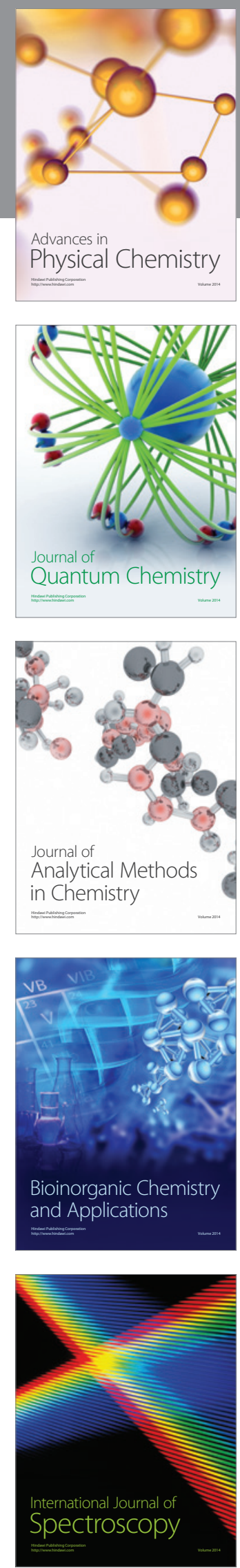